\title{
Tentando compreender Prometeu e Dionísio na mira da violência*
}

\author{
Sueli Aparecida Itman Monteiro ${ }^{\star \star}$
}

RESUMO: O artigo trata de pesquisa realizada em uma Escola de periferia considerada problemática por receber alunos de uma gangue da cidade. Procura-se aqui complexificar o tema da violência, buscando uma maior amplitude de olhar para tal fenômeno que atinge o espaço escolar.

Palavras-chave: escola, violência, gangue, epistemas, culturas

Um encontro de dois: olhos nos olhos, face a face. E quando estivermos perto, arrancar-te-ei os olhos e colocá-los-ei no lugar dos meus;

E arrancarei meus olhos para colocá-los no lugar dos teus;

Então ver-te-ei com teus olhos

E tu ver-me-ás com os meus. ${ }^{1}$

Vinha de um epistema ${ }^{2}$ desencantado, do qual o econômico e o social tinham que dar conta, e se não davam a ele sua relevância, relevante ele não era. Sim ou não eram as possibilidades de resposta. A razão fechava-se no uno, sem a possibilidade de um talvez. O oficial,

* Este artigo representa, em parte, resumo do segundo capítulo da tese de doutorado da autora, "Luzes, sombras e crepúsculos nas vivências cotidianas de duas escolas de primeiro grau: Sucessos, fracassos, evasões, exclusões". Feusp, 1996.

** Professora doutora do Departamento de Psicologia da Educação da Faculdade de Ciências e Letras da Unesp - Araraquara. Pesquisadora no Cice - Centro de Estudos do Imaginário, Culturanálise de Grupo e Educação, Feusp. 
o institucional e o patente eram visíveis e considerados. O invisível, subterraneamente latente, oficioso e instituinte não aparecia. Faltava captar a relação entre luz e sombra. Negava-se o crepuscular, ${ }^{3}$ o imaginal ${ }^{4}$ e a percepção do "religar". Deparei então com o afeto, com a complexidade, com a diversidade, a alteridade, e a ambivalência. Uma "razão aberta" encandesceu-se diante de meus olhos, amparando-me ante um universo de todas as possibilidades. Mergulhei. Reencantei-me e hoje estou aqui. Não falo por todos, falo apenas pelo meu sentir. Não faço generalizações. O que relato está territorializado no seio de identidades microgrupais. Vivem o momento de seus epistemas. Sentem, agem e pensam de modo único. Constroem suas cotidianidades tal qual a lógica própria que lhes rege o existir.

Dessa forma, falo como quem tece uma paisagem, intransferível para outro cenário. Falo ilustrativamente. Cada leitor que realize sua "bricolage" para o momento único que possui diante de si, porque minha intenção não é persuadir, convencer. Apenas poetizo o trivial, deixando no ar a possibilidade de um outro olhar, o mesmo que me leva a caminhos reumanizados como educadora que sou.

Transpus os muros escolares. Fiquei impressionada. Tudo estava tão bonito, limpinho. Um roseiral à esquerda deixava um agradável perfume no ar. Em busca de maiores informações sobre uma gangue de adolescentes organizada naquele bairro, recorri àquela Escola porque uma de suas professoras relatara-me que alguns de seus membros estudavam ali. $O$ fato motivava-me para um estudo em razão das notícias que circulavam sobre os pequenos delitos, que sempre culminavam em exercício de violência no acaso, atemorizando estudantes e moradores em geral daquele bairro. Desejava entender, a partir de suas próprias versões, o que levava aqueles jovens a transgredir as regras sociais. A posição da mídia local eu já conhecia. Em geral, sugestões como "violência com violência se paga", "é preciso pulso forte", "a escola está falhando através de suas regras brandas" estavam associadas ao discurso de setores conservadores que visavam à promoção política pela mídia. Discordava de tais posições e entendia que a análise e a busca de caminhos para o fenômeno da violência e da transgressão careciam de uma amplitude de olhar que se afastava dessas noções estigmatizadoras do diverso. Para não incidir no mesmo erro, que tantos outros já haviam cometido através de seus generalismos, reducionismos e simplismos, procurei ancorar-me nas obras de Edgard Morin, Michel Maffesoli, Gilbert Durand, J.C. de Paula Carvalho, M.C. Sanches Teixeira, M.R. Silveira Porto, H. Suano e A.M. Guimarães. 
Entendia que para estudar o fenômeno da violência não bastava apenas trabalhar umas poucas opiniões e alguns fatos isolados; era preciso uma ação mais ampla, complexa, que me garantisse a totalidade de olhares, que me permitisse apreender a "bela e a fera" naquilo que elas se aproximavam, se tocavam e se distanciavam, no que tinham de semelhante ou de diferente e a potência que Ihes animava.

Assim, o trabalho que pretendia ocupar parte de um semestre na Escola, pela necessidade de um maior aprofundamento dos matizes ali apresentados, alongou-se por dois anos e, pela sua densidade, tornou-se parte de minha tese de doutorado, orientada pela professora Maria Cecília Sanchez Teixeira e defendida na Faculdade de Educação da USP em 1996.

Durante o tempo em que lá estive, entrevistei diretores, professores, secretárias, inspetores, serventes, merendeiras, alunos e seus familiares. Acabei por levantar suas histórias de vida, seus sonhos e medos, os meios encontrados para solucionar dificuldades cotidianas, os mitos, as crenças e os valores, as produções orais, escritas, cantadas e pintadas, a poesia de suas almas, as máscaras assumidas e as comédias e tragédias que inevitavelmente se impregnavam ao cotidiano escolar. Em alguns momentos, a pesquisadora que habita em mim acordava; noutros, a educadora se levantava e trabalhava como nos velhos tempos de magistério de primeiro e segundo graus. Palpitei no planejamento da escola, propus atividades didático-acadêmicas, e trabalhei com duas salas, uma de quinta série e outra de sétima série, que abrigavam os garotos da gangue. Dentre as tantas atividades realizadas com eles durante o tempo em que lá fiquei, uma sobressaiu-se pela importância quantitativa e qualitativa para o mapeamento da cultura microgrupal. O questionário individualizado "Hoje eu sou o repórter" teve dois objetivos: o primeiro foi o de não perder informações que porventura tivessem passado despercebidas durante as sessões em que ocorria o relato oral dos alunos das séries que nos receberam. O segundo objetivo foi o de propiciar a esses adolescentes a possibilidade de ficarem motivados a buscar fatos de suas próprias histórias de vida. Organizei um questionário básico inicial e apresentei o mesmo aos diretores e professores da escola. Fiquei surpresa com as sugestões significativas obtidas. Cada aluno tornou-se investigador de sua própria vida. Relatados e discutidos os produtos de suas coletas em sala de aula, e em seguida recolhidos, pude verificar a freqüência e a porcentagem das respostas dadas, bem como a lógica e a construção do discurso, e até mesmo a maneira como se expressavam através da escrita. A partir dessa atividade, foi possível detectar o quanto sabiam, ou não, sobre suas origens 
e sobre os caminhos percorridos pelos seus avós, pais e irmãos. Além disso, a forma como a atividade foi proposta estabeleceu um elo imediato com as famílias. Em muitos questionários percebi caligrafias diferentes na mesma página, e então soube que esse instrumento, rudimente socializado, criara um momento de religar ${ }^{5}$ e de reflexão da pequena família. ${ }^{6}$ Escrito à mão e depois reproduzido, porque a maioria das pessoas que teriam contato com ele tinha baixa escolaridade, esse questionário ficou dividido em seis grandes blocos de perguntas que, trabalhadas em categorias de análise, acabaram por se constituir, ao todo, em 60 questões. Do primeiro ao quinto bloco (constituído por perguntas "abertas" e "fechadas") foram construídas questões voltadas para os dados do próprio aluno, de seu pai, de sua mãe, de seus irmãos e avós. No sexto bloco, foram apresentados temas relativos à vida que levavam, questões sobre os casos alegres e tristes vivenciados, os medos que tinham, fossem naturais ou sobrenaturais, e, principalmente, sobre os sonhos e as esperanças que acalentavam para o presente e para o futuro. Foi possível perceber como redundavam nessas vidas a migração (avós), a luta por melhores condições de vida e trabalho (pais), o sonho de encontrar o paraíso no "aqui e agora" (filhos). Diante de tais nuanças apresentadas, dei-me conta de que precisaria de um batismo simbólico para identificar mentalidades míticas diferenciadas.

Tão rara beleza merecia ser poeticamente tratada. Eis que Maffesoli, em seu texto "A cultura pós-moderna" (1990), adotou o mito de Prometeu para identificar, dentre outras características, o projeto de vida, o mito do louvor ao trabalho, na ordem e no progresso, como elemento vital da mentalidade grupal, e, por outro lado, o mito de Dionísio por personificar no grupo afetual ${ }^{7}$ o amor ao ócio, o presenteísmo, a ausência de projeto, o orgiasmo ${ }^{8}$ e a idolatria ao corpo. Durand (1983, p. 10) nos lembra que esses universos míticos comportam a pregnância de um mito oficial, e concomitante, pelo menos mais um mito oficiosamente dissidente, que encarna a sombra, o subterrâneo, daquele que se constitui no momento o lado iluminado do fato.

Iniciado o processo de entrevistas, os diretores relataram os efeitos dos atos dos garotos da gangue no interior da escola. Por exemplo, a dissolução de um grupinho no interior da escola, composto por garotos da gangue, resultou no apedrejamento das instalações escolares. Chamada a polícia, responderam-lhes: "pode chamar, somos de menor". Para os diretores, a gangue, que era composta por quase 200 elementos, trazia reflexos nefastos para o cotidiano escolar, na medida em que alguns de seus com- 
ponentes que lá estudavam criavam encrenca, geravam brigas por causa do tráfico de drogas, e em um dos fatos graves ocorridos, por causa da namorada de um dos garotos da gangue, um aluno quase chegara à morte. Nessas brigas, objetos cortantes como facas e tesouras, ou até mesmo as carteiras da escola, tornavam-se armas. Nas festas escolares, abertas à população, várias gangues se encontravam e ficavam fazendo duelos de dança, o que inevitavelmente acabava em confronto violento. A conclusão a que os diretores chegavam, após tais fatos, era que a Escola não sabia trabaIhar nem mesmo com o universo cultural que dava identidade a esses grupos (danças, gírias, roupas) e que, por outro lado, a lei estava sendo feita para proteger e fortalecer o "bandido". Um dos diretores defendia a idéia de que, por meio da educação, primeiro deveriam ser incutidos na consciência do aluno os seus deveres, para que depois ele soubesse os seus direitos. Para os diretores, os grandes geradores do fenômeno da violência eram a televisão e o nível socioeconômico das famílias. Como agravante, a falta de dinheiro levava tais crianças e adolescentes à prostituição. Já a falta de educação e a desestruturação familiar desencadeavam a violência no interior da própria família, incluindo-se aí os casos de abuso sexual. Segundo os diretores, para a maioria dos pais desses alunos a Escola tinha a função não mais de alavanca social, mas sim de guardiã alimentadora de seus fiIhos, porque era o único espaço institucionalizado que os aceitava. Os pais também acreditavam que a Escola pudesse realmente estabelecer padrões de conduta para os filhos (aqueles que eles mesmos não haviam conseguido obter através dos castigos físicos aplicados), a fim de que, regrando-se, pudessem vir a enquadrar-se na ordem do sistema produtivo, ser recompensados e conseguir ter uma vida diferente, de progressos, melhor do que aquela que viviam. Porém, naquele momento, quando a alimentação oferecida pela Escola era algo básico para os pais e seus filhos, ao centro colocava-se a figura da grande mãe, a merendeira, que a todos conhecia com profundidade, citando-os pelo nome e por suas histórias de vida. Ninita, coração de mel, que a todos consolava e aconselhava com suas doses de amor, incluindo-se aí diretores e professores, tornava sua cozinha o grande útero da escola. Para ela, todos aqueles meninos eram "coitadinhos" e eles não podiam fazer as coisas de outra maneira, se a vida lhes havia ensinado com "ferro e fogo". Por isso, sempre que podia cobrava-Ihes que mudassem a conduta e que aproveitassem o ensino para melhorar de situação, ter uma profissão, sair daquela vida.

Já as "meninas da secretaria" viam esses alunos como pouco conhecedores de suas origens, às vezes pais não sabiam o nome de registro dos filhos e filhos não sabiam o dos pais. Uma parcela deles era 
itinerante, indo de uma escola a outra várias vezes ao ano. A Escola servia-Ihes como espaço para encontrar os amigos de fé (principalmente das seitas evangélicas), ou de diversão (para conversar, dançar, namorar). Traziam alguns preconceitos em suas bagagens. Um deles se referia à permanência de um grupo de alunos ciganos que durante parte do ano freqüentava a Escola. Se sumia alguma coisa na sala, logo eles já apontavam algum cigano como o responsável pelo fato, e em todas as vezes que se identificou um culpado, esse não era um dos meninos ciganos. Para as "meninas da secretaria", a garotada da gangue não fazia parte de nenhuma organização político-partidária, mas tinha um discurso bastante elaborado quanto a seus direitos como alunos, o que chegava a incomodar, pois isso os diferenciava dos demais. Eram atuantes no Centro Acadêmico da Escola, haviam colocado a biblioteca para funcionar durante a semana e a quadra de esportes aos sábados e domingos, permitindo que as famílias do bairro também usufruíssem desse benefício. Ajudavam a organizar as festas escolares. Desenvolviam uma forte amizade no grupo, que os levava a uma socialização de tudo o que possuíam. Em nome da amizade grupal aceitavam que uma garota, depois de ter namorado, terminasse o namoro e iniciasse outro relacionamento, desde que também fosse com um garoto do grupo. Porém, em se tratando da convivência com pessoas que não pertenciam ao grupo, não aceitavam conselhos e viviam uma relação dúbia que ia da passividade à agressividade. Para os inspetores dos alunos e serventes, a relação que os alunos da gangue estabeleciam com os colegas nos intervalos de aula não permitia que fosse identificado o que estava ocorrendo, se eram apenas brincadeiras de corpo ou brigas de fato, tal a dureza expressa em seus gestos. Para eles, a própria aparência do pessoal da gangue já os diferenciava, com suas calças arregaçadas até os joelhos, brincos e correntes presos ao nariz e às orelhas, tatuagens, anéis com sinais de caveira e jaquetas com desenhos parecidos. Segundo os inspetores e serventes, esses sinais também eram gravados nas carteiras e paredes internas e externas da Escola. Quando desejavam protestar contra algo ocorrido, pichavam frases relativas ao fato. Por exemplo, certa vez, após uma professora (de que não gostavam porque vivia lhes passando sermão acompanhado de palavras ofensivas) condenar o uso de drogas, eles picharam nas paredes externas da sala de aula, com letras enormes: "Olha, gente... A droga é a paz dos loucos... E a loucura dos que têm paz". Porém, apesar de haver uns poucos professores considerados "chatos" pelos alunos, uma boa parte deles vivia em paz e conseguia realizar a docência. Para os primeiros, esses alunos eram bandidos que não 
deveriam estar na escola; deveriam estar num reformatório judicial, pois eram violentos e promíscuos. Para esses docentes, a vida de professor era considerada "dura" porque eles tinham de conviver com esse tipo de gente e ainda por cima ganhavam mal. Como não tinham um bom relacionamento com os alunos, pouco conseguiam realizar em termos de trabalho docente. Já os professores mais flexíveis mantinham um bom relacionamento com os alunos, porque, segundo afirmavam, gostavam daquela clientela e da Escola onde estavam, e porque sentiam que "trocavam energia" com aqueles garotos, pois, apesar da vida sofrida, cheia de traumas e carências que tinham, viviam uma irreverência cheia de alegria que os contagiava.

Dentre as tantas horas de conversa que pude ter com aqueles docentes, percebi que privilegiavam formar a informar; procuravam passar modelos de vida para os alunos, e sempre se colocavam disponíveis para escutar, aconselhar, encaminhar. Conheciam cada história em profundidade; assim, comungavam a angústia do aluno homossexual espancado pelo padrasto, da garota bolinada pelo pai com a conivência silenciosa da mãe, do garoto cujo pai morrera de Aids e cuja mãe já estava em estágio terminal; dos pequenos delitos e das tentativas que cada um fazia para reverter a sina. Não concordavam com os atos delinqüentes praticados, mas compreendiam suas causas, na oficiosidade de cada aluno, e por isso procuravam orientá-los sobre suas questões mais íntimas de forma espontânea, e, quando possível, inseriam em seus conteúdos programáticos tais informações. Certa vez, um dos professores afirmou: "Por isso, eu sou da opinião que ainda salvar o que é bom não interessa, interessa salvar o que não presta".

Diante de opiniões tão diferentes emitidas sobre uma mesma clientela, por vezes parecia-me que estavam a falar no crucificado, outras vezes no crucificador. No que toca ao meu contato com os alunos, desde o princípio a minha presença entre eles foi bem aceita, e todas as atividades semanais apresentadas foram realizadas com prazer. Em geral, eram atividades lúdicas, em sala, no pátio ou fora da escola, que em si favoreciam as vivências microgrupais ali experimentadas. A diversidade complexa de cada microuniverso cultural permitia que epistemas de vida, embora territorializados no mesmo espaço, fizessem com que cada grupo visse, entendesse e agisse de acordo com a lógica que lhe imprimia a vida. A mim, parecia que as percepções desses grupos se apresentavam diferentemente em relação ao que esperavam da mesma Escola. De acordo com seus paradigmas de vida, enxergavam-na a partir de uma 
perspectiva única, que levava, por exemplo, dentre os tantos grupos de afinidade ali identificados, os garotos evangélicos a buscar o conhecimento no cotidiano escolar para poder melhor divulgar sua fé, e, num projeto de vida mais distante, a estar aptos a uma profissão que lhes permitiria 0 bem-estar da futura família, amparada por laços de fé, num amor fraterno e virginal. Para a garotada da gangue, aquele era o espaço da socialidade, onde se encontravam a fim de namorar, rir, brincar, dançar, jogar, contar seus casos, alimentar-se, acertar as contas com quem Ihes incomodava, e esquecer a briga da família, o pai alcoolizado, a surra levada sem saber a causa, a bolinação incestuosa, a falta de comida, o desafeto desrespeitoso, o cansaço provocado pelas atividades domésticas tais como limpar, cozinhar e cuidar dos irmãos, as atividades fora de casa, às vezes ajudando os próprios pais em seus delitos, e, por fim, participar das aulas, principalmente daquelas em que o professor lhes dirigisse a fala respeitosa, que Ihes elevasse a auto-estima. Não tinham projetos de vida, não temiam ser reprovados; o diploma viria naturalmente um dia, porque acreditavam que venceriam a estrutura oficial de ensino pelo cansaço e porque sabiam que até para ser varredores de rua precisavam do certificado de conclusão da oitava série. Eles deixavam claro que viviam "o aqui e agora" e que, naquele instante, só o que contava era o momento presente. Para eles, aquele era principalmente o espaço onde suas práticas simbólicas encontravam leito para circular e dar asas a sua imaginação. Era o único legado do qual a sociedade lhes permitia usufruir. A seqüência de perdas e de exclusões que viviam exorbitava o medo em relação à morte e em relação à ausência de bem-estar social que se personalizava quer seja no receio à Aids, quer seja na figura do ladrão e do assalto. Esses adolescentes viviam uma relação dúbia com o perigo. Colocavam-se na posição de vítimas e, ao mesmo tempo, amalgamavam-se, reconheciamse na gangue que intimidava o bairro. Aliavam-se numa cumplicidade aterrorizada, dizendo: "quem não está dentro está fora, e corre perigo". Temiam e idolatravam os "marginais" ao mesmo tempo, porque eles tinham a coragem para afrontar a ordem vigente e para se rebelar contra a falta de direitos que o cidadão do bairro enfrentava. Tornavam-se violentos, marginais, para ganhar uma identidade entre os seus, para serem reconhecidos e temidos a fim de combater o próprio temor subterrâneo que os dominava: a certeza da morte mais próxima e mais certa do que para outros garotos. Muitas vezes, escutei histórias tristes, de horror, vividas ou provocadas por eles; outras vezes, muito me diverti com suas anedotas pitorescas e pude colorir meus olhos com toda aquela sincronia corporal que Ihes permitia parecer um só corpo. Quem não os conhecesse e os vis- 
se dançando, se resvalando, pensaria logo que estavam festejando algo especial. Estavam mesmo. Festejavam aquele precioso momento, em que o "estar-junto" se tornava o fato mais importante de suas vidas.

Hoje, passado algum tempo, ainda guardo suas histórias com carinho. Tenho uma amiga que, sorrindo com certa ironia, diz: "Ah!...você e seus meliantes".

Entendo que, como ela mesma diz, "esse olhar cor-de-rosa" é que me permite interpretar o amor e seu contrário - a violência - como sentimentos e ações naturais, primários no ser. Eliminar um desses pólos, que juntos estabelecem a harmonia na diferença mediante a correlação ambígua de suas forças, seria o mesmo que eliminar o próprio ser. É essa ambigüidade que permite à pessoa construir sua identidade única, necessária à vivência no grupo afetual. Porém, creio que a desordenação intensa desses sentimentos, fundada no desequilíbrio entre esses parâmetros grupais, é que provoca a transgressão dos mesmos. Ocorrem os amores obsessivos tanto quanto o seu contrário, ou seja, as violências exacerbadas, que acabam por extrapolar os limites da vida. Nesse caso, tanto o amor quanto a violência deixam de ser um jogo grupal, de sedução, em que a grande intenção é o toque, o resvalo de corpos, a brincadeira do "empurra-empurra" a fim de medir forças, fortalecer hierarquias, amparadas pelo prazer físico disfarçado em cena de violência, para, então, se constituírem de fato em ameaça à sobrevivência do outro.

Numa relação de luz e sombra, quando um pai tenta coibir um fiIho com um castigo físico ou moral, ele colabora para que o lado de sombra peculiar à identidade do garoto, o lado transgressor, vá se ampliando. Quanto mais reprimida a face de sombra, mais ela se estende por sobre a luz, tornando-se mais visível e incontrolável.

Através do relato acima descrito, podemos perceber que quando as diferenças de mentalidade apresentadas pelos binômios pais-filhos, professor-aluno e aluno-aluno não encontram um ponto de tangência, de mutação, que lhes permita a sincronia momentânea estabelecida por meio de valores acordados, passam a ser sustentadas pelo conflito constante, o qual leva a uma saturação das partes, ao estresse, ao pânico, à neurose, à exacerbação do medo natural que temos em relação à morte.

Eu entendo que os acontecimentos que vêm ocorrendo arrepiam os cabelos de pais, de alunos e de educadores. Como identifiquei, várias mentalidades se resvalam no cenário escolar. Muitas vezes o resvalar não chega a provocar algo grave; porém, em outros momentos, aten- 
ta-se contra a vida mental e física das pessoas envolvidas no fenômeno. Os mais enérgicos dirão: "É fácil você se encantar quando fala nos bandidinhos, nunca lhe fizeram nada". E eu respondo: eu e minha família fomos tanto ou mais vitimizadas do que a maioria das pessoas que passaram por um bom susto, mas nem por isso deixo de acreditar que é na escola que essas crianças e esses adolescentes encontram a chance de trabalhar as questões ligadas à violência, porque, se vitimizam, também são vitimizados. Cada grupo é um grupo, e possui seu universo cultural; pode ser que os grupos das escolas nas quais oriento meus estagiários e faço minhas pesquisas sobre violência, sexualidade, epistemas, entre outros temas, sejam mais brandos, ou que meu olhar, ao iluminar a sombra e sombrear a luz inerente aos cotidianos, abrande a dureza daquela análise que olha apenas do ponto de vista do cidadão estabelecido. Atualmente, colaboro na Escola "Dorival Alves", em Araraquara (SP), que tem tantos ou mais problemas do que os relatados acima. Lá cheguei em meio à redistribuição da Rede Física. Professores de muitas escolas, ali reagrupados, não encontravam os velhos pares que outrora Ihes estenderam a âncora nos momentos difíceis; alunos insatisfeitos, vindos de outras escolas e de outros espaços demarcados por suas gangues de origem, aglomeravam-se, trombavam, querendo demarcar o novo espaço pelo uso da força. Ouvia-se muito a palavra "caos" nos corredores. Aos poucos, esse mesmo caos permitiu que fôssemos identificando um novo perfil, uma vocação fruto da soma das nossas diferenças. Por meio de um projeto ético-pedagógico, delineado nas reuniões semanais, passamos a mapear as culturas pregnantes e identificamos os alunos que, para os tantos modelos de contravenção social apontados, não apresentaram sequer um modelo de vivência de justiça, e que, apesar das tantas experiências ruins que possuem, atribuem a si próprios algumas qualidades, tais como amor e amizade. Porém, não as atribuem ao ser humano em geral, com exceção do modelo positivo atribuído ao "bom professor", aquele que respeita, conversa, dá aula explicando. Mitos religiosos e políticos sequer foram mencionados. Ídolos do universo artístico também foram negligenciados, e somente em pequena escala as "globais" Xuxa e Angélica foram citadas como possíveis modelos de justiça. Posso concluir que apesar de tantas críticas recebidas pela escola, de modo geral, naquelas em que venho pesquisando ao longo desses anos, estão sendo construídos modelos valorativamente positivos, ao contrário dos dados que me indicam que algumas famílias já não fornecem tais modelos importantes ao processo de hominização de seus fiIhos. $O$ antigo útero protetor, o esconderijo de todas as aflições, chama- 
do por Bachelard como "casa materna", hoje muda de endereço e desloca-se para a escola. Talvez, mais do que nunca, a clientela esteja atribuindo um novo conceito ao papel social que a escola desempenha; não mais aquilo que toca à busca do conteúdo, da profissionalização, do projeto de vida, mas sim da construção dos valores de bondade, amizade, solidariedade, justiça. Quando falamos em cidadania, não dá para concebê-la sem que esses conceitos sejam vivenciados. Quando falamos em violência no interior da escola, não dá para começar a discussão sem que seja estabelecido um código de ética grupal que venha delimitar conceitos e ações. Ao mesmo tempo em que o agressor incomoda, ele também é incomodado, e, portanto, nada melhor do que construir - dentro do projeto pedagógico de cada escola - as bases para uma sociabilidade que não venha a negar o conflito, mas que estabeleça os valores e os limites de suas transgressões. Recuperar as identidades culturais, grupo a grupo, pelo levantamento de suas vivências, quer seja através da história oral, da música, da dramatização ou da poesia da alma, que epifaniza a tragédia e a comédia contidas no fenômeno da violência, tem me mostrado que isso ajuda a estabelecer elos de solidariedade e de recomposição da socialidade. Essas atividades, tão simples de serem organizadas por qualquer educador bem intencionado, desde que arroladas a um planejamento global das atividades escolares, permitem emergir os processos inconscientes; aqueles que geralmente levam as pessoas a tomar atitudes aparentemente incompreensíveis aos olhos dos outros. Vivenciar, principalmente através da dramatização, os processos de violência e de sua transgressão permite que os mesmos sejam reordenados de tal forma que se tornem compreensíveis. Sei que a escola não dá conta do universo global da violência, as causas sociais são por demais perversas; porém, as pessoas buscam essa instituição, atribuem-Ihe um grande valor. Então, na medida em que faltam modelos, por que não começamos a tecê-los conjuntamente, sem que sejam perdidos de vista os "Prometeus" e os "Dionísios" da vida? Para os que querem o "projeto", que o mesmo seja preservado; para os que buscam o lúdico, o afetual, que nela o encontrem, dentro de uma razão que ouse acreditar na ação eticamente construída pela harmonia na diferença.

Mais importante do que a ciência é o seu resultado, Uma resposta procura uma centena de perguntas. Mais importante do que a poesia é o seu resultado, Um poema invoca uma centena de atos heróicos. ${ }^{9}$ 


\title{
Notas
}

MORENO, J.L. "Divisa”. Traduzido de "Einladung zu einer Begegnung", Viena, 1914.

2. Modos de sentir, pensar e agir que regem o viver de uma comunidade e/ou o pensamento fundante de um grupo científico.

3. Supostamente a zona de divisa entre os "regimes diurno e noturno de imagens" apresentados por G. Durand (83). O crepúsculo é o limite entre o dia e a noite e portanto nos tráz a idéia da face velada do fenômeno, do seu todo indefinido.

4. Arcabouço do sentir-pensar, pensar e agir da pessoa e de seu microgrupo, aquele que abarca os arquétipos primordiais, as práticas simbólicas, os ritos, as crenças e os valores organizados naquele universo cultural.

5. Vem de religare, ou seja, princípio de todo o sentimento de sagrado que dá identidade e une, através de crenças e afinidades, o microgrupo.

6. Família consangüínea composta pelos pais, avós, primos e filhos; diferentemente de outras organizações, não consangüíneas, encontradas. A exemplo da segunda situação: a agregação de amigos e parentes distantes vivendo familiarmente, sob o mesmo teto. Ou ainda, a idéia recorrente de família encontrada entre os jovens da gangue, onde esse conceito ultrapassava aquele da "pequena família" e, ampliado, era concebido como laço de solidariedade estabelecido entre os membros do grupo, vivenciado através do "estar-junto".

7. Conceito expresso na obra de M. Maffesoli; é o elo de afeto e de solidariedade vivido de forma plena no interior do microgrupo, onde sentimentos, códigos e valores identificam e diferenciam seus membros dos demais.

8. Modos de o microgrupo expressar sua alegria, sua cultura, seus relacionamentos afetuais, dentro de uma perspectiva de comunhão na bebida, na comida, na doença, na música, no amor...

9. Vide nota 1

\section{Trying to understand Prometheus and Dionysos under the sight of violence}

\begin{abstract}
The article deals with a research which took place at a school located in the outskirts of a town which is considered troublesome for welcoming students from the town gang. The intent here is to make the violence issue more complex, searching for a higher amplitude when looking at such phenomenon that reaches school space.
\end{abstract}




\section{Bibliografia}

BACHELARD, G. A poética do espaço. São Paulo: Martins Fontes, 1989.

DURAND, G. Mito e sociedade. A mitanálise e a sociologia das profundezas. Lisboa: A regra do jogo, 1983.

GUIMARÃES, A.M. "A depredação escolar e a dinâmica da violência". Tese de doutorado. Campinas: Unicamp, Faculdade de Educação, 1990.

ITMAN MONTEIRO, S.A. "Luzes, sombras e crepúsculos nas vivências cotidianas de duas escolas de primeiro grau: Sucessos, fracassos, evasões, exclusões". Tese de doutorado. São Paulo: USP, Faculdade de Educação, 1996.

MAFFESOLI, M. A conquista do presente. Trad. Marcia Sá Cavalcante. Rio de Janeiro: Rocco, 1985.

. Dinâmica da violência. São Paulo: Biblioteca Vértice, 1987(a).

. O tempo das tribos: O declínio do individualismo nas sociedades de massa. Rio de Janeiro: Forense-Universitária, 1987(b).

. "A cultura pós-moderna". Colóquio. São Paulo: ECA/USP, 1990 (mimeo).

MORIN, E. O enigma do homem. Para uma nova antropologia. $2^{\text {a }}$ edição. Trad. Fernando de Castro Ferro. Rio de Janeiro: Zahar, 1979.

PAULA CARVALHO, J.C. Antropologia das organizações e educação: Um ensaio holonômico. Rio de Janeiro: Imago, 1990.

. "A culturanálise de grupos: Posições técnicas e heurísticas em educação e ação cultural”. Ensaio para titulação. São Paulo: USP Faculdade de Educação, 1991.

SANCHEZ TEIXEIRA, M.C. "Escola: Exclusão e representação (notas para uma reflexão)". Revista da Faculdade de Educação no 1. São Paulo: USP, Faculdade de Educação, v. 18, jan.-jun., 1992, pp. 20-32.

"Imaginário, cultura e educação: Um estudo socioantropológico de alunos de escolas de primeiro grau". Tese de livre-docência, Faculdade de Educação, USP, 1994. 
SILVEIRA PORTO, M.R. "Escola rural: Cultura e imaginário". Tese de doutorado. São Paulo: USP, Faculdade de Educação, 1993.

SUANO, H. "Cultura e imaginário sócio-organizacional: Um estudo sócioantropológico no universo de uma organização educativa". Tese de doutorado. São Paulo: USP, Faculdade de Educação, 1993. 